\title{
Abnormal fluid homeostasis in apelin receptor knockout mice
}

\author{
Emma M Roberts, Michael J F Newson, George R Pope, Rainer Landgraf ${ }^{1}$, \\ Stephen J Lolait and Anne-Marie $\mathbf{O}^{\prime}$ Carroll \\ Henry Wellcome Laboratories for Integrative Neuroscience and Endocrinology, University of Bristol, Bristol BS1 3NY, UK \\ ${ }^{1}$ Max Planck Institute of Psychiatry, D-80804 Munich, Germany \\ (Correspondence should be addressed to A-M O'Carroll; Email: a.m.ocarroll@bristol.ac.uk)
}

\begin{abstract}
The apelinergic system, comprised of apelin and its G protein-coupled receptor (APJ; APLNR as given in MGI Database), is expressed within key regions of the central nervous system associated with arginine vasopressin (AVP) synthesis and release as well as in structures involved in the control of drinking behaviour, including the magnocellular neurones of the hypothalamus, circumventricular organs, and the pituitary gland. This localisation is indicative of a possible functional role in fluid homeostasis. We investigated a role for APJ in the regulation of fluid balance using mice deficient for the receptor. Male APJ wild-type and knockout $\left(\mathrm{APJ}^{-/-}\right)$ mice were housed in metabolic cages to allow determination of water intake and urine volume and osmolality. When provided with free access to water, $\mathrm{APJ}^{-/-}$mice drank significantly less than wild-types, while their urine volume and osmolality did not differ. Water deprivation for $24 \mathrm{~h}$
\end{abstract}

significantly reduced urine volume and increased osmolality in wild-type but not in $\mathrm{APJ}^{-/-}$mice. Baseline plasma AVP concentration increased comparably in both wild-type and $\mathrm{APJ}^{-1-}$ mice following dehydration; however, $\mathrm{APJ}^{-/-}$ mice were unable to concentrate their urine to the same extent as wild-type mice in response to the V2 agonist desmopressin. Analysis of c-fos (Fos as given in MGI Database) mRNA expression in response to dehydration showed attenuation of expression within the subfornical organ, accentuated expression in the paraventricular nucleus, but no differences in expression in the supraoptic nucleus nor median pre-optic nucleus in $\mathrm{APJ}^{-/-}$mice compared with wild-type. These findings demonstrate a physiological role for APJ in mechanisms of water intake and fluid retention and suggest an anti-diuretic effect of apelin in vivo.

Journal of Endocrinology (2009) 202, 453-462

\section{Introduction}

Apelin, a novel 36 amino acid peptide originally isolated from extracts of bovine stomach (Tatemoto et al. 1998), mediates its actions through the G protein-coupled (GPCR) apelin receptor (APJ; APLNR as given in the MGI Database). In addition to apelin-36, other possible isoforms of the peptide, including the pyroglutamyl form of apelin-13 (pGlu-apelin13) and apelin-17, have been discovered in rat hypothalamic extracts and plasma (De Mota et al. 2004). Synthetic peptides pGlu-apelin-13 and apelin-17 bind to APJ and exhibit greater biological activity than the parent peptide on the human (Habata et al. 1999, Zou et al. 2000, Medhurst et al. 2003) or rat APJ (De Mota et al. 2000). In recent years cDNA sequences for human, rat, and mouse APJ have been determined (O'Dowd et al. 1993, Devic et al. 1999, O'Carroll et al. 2000), with closest identity (31\%) found to the angiotensin II (AngII) receptor, type AT1a.

The apelinergic system has a widespread but selective expression in the central nervous system (CNS) implicating it in the regulation of a number of physiological processes (Lee et al. 2000, O'Carroll et al. 2000, Reaux et al. 2002).
Significantly, APJ mRNA expression and apelin immunoreactivity are present in magnocellular neurones of the hypothalamic paraventricular (PVN) and supraoptic nuclei (SON), sites that control the hypothalamic-neurohypophysial system (HNS), the pituitary gland and within the circumventricular organs (CVOs, structures involved in the control of drinking behaviour; De Mota et al. 2000, Reaux et al. 2001, 2002, Brailoiu et al. 2002, O'Carroll \& Lolait 2003).

The key CNS site integrating neuroendocrine adjustments to water homeostasis is the hypothalamic PVN. Arginine vasopressin (AVP), a major neurohypophysial hormone within the HNS, is synthesised in magnocellular neurones of the hypothalamic PVN and SON (Burbach et al. 2001) that project through the median eminence to the neurohypophysis and form the hypothalamo-neurohypophysial tract (Antunes-Rodrigues et al. 2004). The HNS is the primary source of AVP and the related peptide oxytocin (OT) that are secreted into the systemic circulation from neurones terminating in the posterior pituitary. These magnocellular neurones are themselves innervated by osmoresponsive neurones originating in the CVOs, including the organum vasculosum of the lamina terminalis (OVLT), subfornical 
organ (SFO), median pre-optic nucleus (MnPO), and median pre-optic area. Elevated plasma osmolality and/or decreased plasma volume, as seen during periods of water deprivation, stimulate activity within the CVOs-HNS resulting in the secretion of AVP into the circulation (Antunes-Rodrigues et al. 2004, McKinley et al. 2004). In the kidney plasma AVP acting at the AVP V2 receptor increases renal collecting cell permeability via increased translocation, synthesis, and expression of the water channel aquaporin-2, so promoting water retention (Knepper \& Inoue 1997).

Previous studies have demonstrated expression of APJ to be differentially regulated in rats in response to fluid deprivation and increased dietary salt within brain areas such as the PVN and $\mathrm{SON}$, indicating a role for the apelinergic system in fluid homeostasis (O'Carroll \& Lolait 2003). In addition, in the neurohypophysial axis, the physiological effects of apelin appear to be mediated by AVP but inconsistent effects have been reported. There is evidence that apelin acts to counteract AVP actions through regulation of AVP neurone activity and AVP secretion (Reaux et al. 2001, De Mota et al. 2004, Reaux-Le Goazigo et al. 2004, Azizi et al. 2008). Additionally, a study on water deprivation showed a significant increase in both the number and labelling intensity of magnocellular apelin-immunoreactive cells in the rat SON and PVN that were significantly reduced after chronic exposure to the AVP V1 receptor antagonist MeTAVP (1- $\beta$-mercapto- $\beta, \beta$-cyclopentamethylene-propionyl)2-(O-methyl)Tyr,Phe-Gln-Asn-Cys-Pro-Arg-Gly-NH ${ }_{2}$; Reaux-Le Goazigo et al. 2004). Repeated i.c.v. injections of AVP resulted in an increase in SON and PVN apelinimmunoreactivity, an effect that could be attenuated by i.c.v. pretreatment with the AVP V1 antagonist, indicating that this effect, like the dehydration-inducted effects, is mediated through AVP V1 receptors. Exogenously administered apelin also reduced the amount of circulating AVP and stimulated diuresis (De Mota et al. 2004). Contrary to these studies are reports that in vitro apelin-13 significantly stimulated AVP release from rat hypothalamic explants (Taheri et al. 2002), while apelin-13 administration onto SON neurones via microdialysis increased the firing rates of AVP cells (Tobin et al. 2008). In this latter study, apelin inhibited both basal and stimulated somatodendritic release of AVP. Apelin and APJ have therefore been linked to the regulation of body fluid homeostasis, in particular to a role regulating the anti-diuretic action of AVP (Lee et al. 2000, Reaux et al. 2001, 2002, Taheri et al. 2002, De Mota et al. 2004, Reaux-Le Goazigo et al. 2004, Azizi et al. 2008), but many contradictions exist that remain to be resolved.

Similarly, a role for the apelinergic system in thirst and drinking behaviour has been proposed, although currently reports also differ with regard to its contribution. In water replete (WR) animals an immediate, short lived (30 min) but significant increase in water intake following i.p. or i.c.v. apelin injection (Lee et al. 2000, Taheri et al. 2002) has been reported, whereas other studies found apelin to significantly reduce water intake up to $12 \mathrm{~h}$ post i.c.v. injection (Clarke et al. 2009) or to have no effect (Reaux et al. 2001, Mitra et al. 2006). Additionally, studies in water deprived (WD) animals have shown regulatory actions of apelin on fluid homeostasis with i.c.v. apelin reducing (Reaux et al. 2001) or having no effect (Mitra et al. 2006) on water intake. However, in mice lacking the apelin gene the dehydration-induced drinking response was comparable with that of wild-type mice suggesting that apelin does not have an apparent role in water intake (Kuba et al. 2007). A peripheral increase in apelin (i.p.) appeared to activate neurones in the CVOs and hypothalamus consistent with the involvement of the apelinergic system in fluid homeostasis (Takayama et al. 2007).

To date, the majority of studies have used exogenous administration of either apelin or AVP to elucidate the role of the apelinergic system in body fluid homeostasis. In this study, we have used APJ knockout (KO) mice to investigate the involvement of APJ in body fluid regulation during normal physiological conditions and water deprivation.

\section{Materials and Methods}

\section{Animals}

Adult male littermates (a mix of the C57BL/6J and $129 \mathrm{X} 1 / \mathrm{SvJ}$ strains) of crosses using mice heterozygous for the APJ mutation (Deltagen, San Carlos, CA, USA) were bred and maintained on site. Prior to the experimental period, animals were housed under controlled light conditions (12 h light: $12 \mathrm{~h}$ darkness cycle, lights on at $0700 \mathrm{~h}$ ) and temperature $\left(21 \pm 2{ }^{\circ} \mathrm{C}\right)$ with free access to standard lab chow and water. All procedures were conducted in accordance with the Animal Scientific Procedures Act (1986), the United Kingdom and the appropriate University of Bristol Ethical Review Process.

Offspring were genotyped at weaning using PCR analysis of DNA isolated from tail clips. Genomic templates were used for PCR analysis with primers directed to the APJ coding sequence (Primers 1, 2, 6, and 7) and to the neomycin resistance gene (contained in the disrupted targeting vector construct; Primers 3, 4, and 5) in a buffer mix: $10 \times$ Hot Start buffer (Continental Lab Products, Northampton, UK; $1 \mu \mathrm{l}$ ), dNTP mix (Perkin Elmer; 1.6 $\mu$ ), primer mix (for Primers 3 and 4: $0 \cdot 2 \mu \mathrm{l}$ of $10 \mu \mathrm{M}$ of each primer; for all other Primers: $1 \cdot 0 \mu \mathrm{l}$ of $4 \mu \mathrm{M}$ of each primer), CLP Hot start polymerase $(0 \cdot 2 \mu \mathrm{l})$, and $\mathrm{dH}_{2} \mathrm{O}$ (to a final volume of $10 \mu \mathrm{l}$ ). Oligonucleotide primers used were as follows: Primer 1 (5'-TGATGGTTACAACTACTATGGGGCT-3 $\left.{ }^{\prime}\right)$ and Primer 2 (5'-GTCAAACTCCCGGTAGGTATAAGTG-3') were used to amplify the wild-type allele, Primer 3 (5'-AgAgGCTATtCGgCTATGACTG-3') and Primer 4 $\left(5^{\prime}\right.$-TTCGTCCAGATCATCCTGATC- $\left.3^{\prime}\right)$ were used to amplify the recombinant allele and Primer 5 (5'-GGG TGGGATTAGATAAATGCCTGCTCT- $3^{\prime}$ ), which was unique to the neomycin cassette, was used in a 'multiplex' 
reaction with Primers 6 (5'-ATGGGGCTGACAACCAGTCTGAATG-3'), and 7 (5'-CACAGTGGCAAAGTCACCACAAAGG- $3^{\prime}$ ) to detect both wild-type and targeted alleles. Negative controls contained no template DNA. PCR conditions were $96^{\circ} \mathrm{C}$ for $15 \mathrm{~min}$, followed by 35 cycles of $96{ }^{\circ} \mathrm{C}$ for $10 \mathrm{~s}, 60^{\circ} \mathrm{C}$ for $30 \mathrm{~s}, 68^{\circ} \mathrm{C}$ for $90 \mathrm{~s}$, with a final extension of $68^{\circ} \mathrm{C}$ for $7 \mathrm{~min}$.

\section{Measurement of fluid intake, urine output, and osmolality}

Mice (8-14 weeks-old wild-type $n=16$; APJ KO $\left(\mathrm{APJ}^{-/-}\right.$) $n=16)$ were individually housed in metabolic cages (Techniplast, Varese, Italy) to examine the effect of APJ deletion on fluid intake, urine output, and osmolality. Animals were weighed and allowed to acclimatise to the cage for $48 \mathrm{~h}$ with free access to crushed lab chow and water. All subsequent measurements and procedures were conducted between 0900 and $1030 \mathrm{~h}$. Mice were given a measured amount $(50 \mathrm{ml})$ of water, and spontaneously voided urine was collected under mineral oil (200 $\mu$ l; Sigma) for $24 \mathrm{~h}$. Basal water intake, urine output, and osmolality (freezing point depression; Roebling Osmometer, Berlin, Germany) were measured. The animals were then divided into two groups, one of which was deprived of drinking water for $24 \mathrm{~h}$ (WD; $n=8)$, while the second group continued to have free access to water (WR; $n=8$ ) after which water intake, urine output, and osmolality were again measured. Mice were killed by decapitation and trunk blood collected for measurement of plasma AVP, while brains were rapidly dissected out, frozen on dry ice, and stored at $-80^{\circ} \mathrm{C}$.

\section{Effect of AVP V2- receptor agonist desmopressin}

To examine the renal responses of $\mathrm{APJ}^{-/-}$mice to AVP, the effect of endogenous AVP was mimicked by exogenous administration of an AVP-V2 receptor agonist, desmopressin (dDAVP; Sigma). Mice $(n=5-6)$ were housed in metabolic cages as described above and, following the appropriate period of acclimatisation, baseline urine samples were collected by bladder massage. Mice were then injected subcutaneously with $1 \mu \mathrm{g} / \mathrm{kg}$ dDAVP or vehicle ( $0.9 \%$ saline) and water bottles were removed. Urine samples were collected from the cage $4 \mathrm{~h}$ after injection and by bladder massage $4 \mathrm{~h}$ after injection. Urine samples were centrifuged briefly to remove debris and osmolality measured by freezing point depression.

\section{Measurement of plasma AVP}

Trunk blood was collected in chilled tubes containing EDTA $(1 \mathrm{mg} / \mathrm{ml}$ blood; Sigma) and aprotinin $(500 \mathrm{KIU} / \mathrm{ml}$ blood; Sigma). Samples were kept on ice and centrifuged at $1690 \boldsymbol{g}$ for $20 \mathrm{~min}$ at $4{ }^{\circ} \mathrm{C}$. Plasma was stored at $-80^{\circ} \mathrm{C}$ until assay. Plasma AVP concentration was determined by specific RIA following extraction with heat-activated LiChroprep Si60 (Merck; Landgraf et al. 1995). The level of sensitivity was
$0 \cdot 1 \mathrm{pg} / \mathrm{sample}$; cross-reactivity of the polyclonal anti-AVP antibody with structurally related peptides including lysine vasopressin and OT was $<0 \cdot 7 \%$. Intra- and inter-assay coefficients of variation were in 6-9 and $9-12 \%$ ranges respectively; all plasma samples to be compared were assayed in the same run.

\section{In situ hybridisation histochemistry}

Sections $(12 \mu \mathrm{m})$ of tissue were cut, thaw-mounted onto polysine-coated slides (VWR, Lutterworth, UK), and stored at $-80{ }^{\circ} \mathrm{C}$ until hybridisation. Specific riboprobes were used to look at neurone activity within the CVOs/HNS and to confirm genotype. All ${ }^{35} \mathrm{~S}$ riboprobes were generated by PCR using 129SV genomic DNA as template. For the mouse, $c-f o s$ (Fos as given in MGI Database primers (upstream 5'-ACAGATCTGCCTGCAAGATCC- $3^{\prime}$; downstream $5^{\prime}$-GTGAGCTCAGGGAGTCGGAGGA-3') corresponding to 2164-2679 bp of a mouse c-fos (Fos as given in MGI Database) gene (Genbank Accession number J00370) were used to generate a $516 \mathrm{bp}$ product. The primers contain the recognition sequences for the restriction endonucleases BglII and SacI. For the mouse AVP, ${ }^{35} \mathrm{~S}$ riboprobe primers (upstream 5'-TGCTGCAGCGACGAGAGCTGCGT-3'; downstream 5'-GCAAGCTTATTTTCCATGCTGT-3') corresponding to bp 2966-3392 of a mouse AVP-neurophysin II gene (Genbank Accession number M88354) were used to generate a $224 \mathrm{bp}$ product. The primers contain the recognition sequences for the restriction endonucleases PstI and HindIII. For the mouse APJ, ${ }^{35} \mathrm{~S}$ riboprobe primers (upstream 5'-GCCCGAATTCACTTCATTCAGCACCATGGAAGAT-3'; downstream 5'-GTCAGGATCCCGGTAGGTATAAGTGGCCCACAGT-3') corresponding to bp 256-549 of a mouse apelin receptor cDNA (Genbank Accession number NM 011784) were used to generate a $293 \mathrm{bp}$ product. The primers contain the recognition sequences for the restriction endonucleases EcoRI and BamHI. Primer restriction endonuclease sites allowed subcloning into pGEM4Z (Promega), and sense and antisense probes were generated using T7 and SP6 polymerases (c-fos antisense: linearised with HindIII and generated with SP6 polymerase; sense: linearised with EcoRI and generated with T7 polymerase; AVP and APJ antisense: linearised with EcoRI and generated with T7 polymerase; sense: linearised with HindIII and generated with SP6 polymerase) with ${ }^{35}$ S-UTP (Perkin Elmer) and the MAXIscript in vitro transcription kit (Ambion, Austin, TX, USA). The integrity of each probe was verified by DNA sequencing.

Hybridisation was carried out as previously described (http://intramural.nimh.nih.gov/lcmr/snge/Protocols/ISHH/ ISHH.html). Slides were exposed to Amersham Hyperfilm MP film for 8 weeks for APJ (reflecting the low abundance of APJ mRNA), 2 days for AVP, and 5 weeks for c-fos at room temperature with appropriate ${ }^{14} \mathrm{C}$-labeled standards (Amersham). No specific hybridisation was detected with sense probes. 
Histology

In order to compare peripheral tissue morphology of wildtype and $\mathrm{APJ}^{-1-}$ mice, a hematoxylin and eosin $(\mathrm{H} \& \mathrm{E})$ stain was carried out on $4 \mu \mathrm{m}$ thick sections of paraffin-embedded, Bouin's (Sigma) fixed organs, including the pituitary gland, adrenal gland, kidney, lung, heart, ovary and testis. Tissue morphology was assessed using light microscopy.

\section{Statistical analysis}

Water intake and urine output were calculated as ' $\mathrm{ml}$ per $24 \mathrm{~h}$ per $20 \mathrm{~g}$ body weight'. All data are expressed as mean \pm s.E.M. Any differences between WR wild-type and WR APJ ${ }^{-1-}$ mice were determined by Student's (unpaired two-tailed) $t$-test. Effects of genotype and treatment were determined by two-way ANOVA with repeated measures and subsequent post hoc tests. Plasma AVP RIA data are expressed as $\mathrm{pg} / \mathrm{ml}$, given as mean \pm s.E.M., and compared using two-way ANOVA. For in situ hybridisation histochemistry (ISHH) data, analysis of the autoradiographic images of probe bound and visualised on film was carried out using NIH Image software (Rasband, version 1.22; http://rsb.info.nih.gov/nih-image/) run on an Apple Macintosh IICi using 2-4 sections from each animal. ISHH was carried out on tissue sections cut from regions of interest (SFO, MnPO, SON, PVN). These regions were delineated by comparison of $\mathrm{APJ}^{-/}$images to wild-type control images cut at the same tissue level. For each image, the region of interest was selected and its mean optical density determined. Using the standard curve, a representative value for that area was obtained; data were expressed as a percentage of the mean for the control group (wild-type/WR) and this was used for statistical analysis. All values to be statistically compared were processed in the same assay to avoid interassay variability. ISHH data are expressed as a percentage of the mean for the control group (wild-type/WR), and compared using two-way ANOVA and post hoc tests. Statistical comparisons were made using GraphPad Prism software. $P<0.05$ was considered statistically significant.

\section{Results}

Characteristics of $\mathrm{APJ}^{-/-}$mice

Mice lacking the APJ gene were bred from APJ heterozygous matings. Absence of the gene in homozygous mutant mice was determined by PCR (Fig. 1A). Analysis of progeny genotypes at weaning showed $6 \%$ to be homologous for the disrupted allele, $28 \%$ to be wild-type and $66 \%$ to be heterozygous for the APJ mutation, indicating a loss of homozygous mutants. However, homozygous survivors were viable and fertile and, besides a significantly lower body weight than wild-type littermates $\left(\mathrm{APJ}^{-/}\right.$26.71 $\pm 0.68 \mathrm{~g}$, wild-type 28.44 $\pm 0.50 \mathrm{~g}, P<0 \cdot 05)$, showed no obviously visible phenotype. Histological analysis of H\&E-stained sections from the pituitary gland, adrenal gland, kidney and lung (Fig. 1B) and heart, ovary and testis (data not shown), did not reveal any apparent morphological differences in $\mathrm{APJ}^{-/-}$mice compared with wild-type littermates. Representative ISHH autoradiographic images showing APJ mRNA expression in sections of heart and PVN from wild-type and $\mathrm{APJ}^{-/-}$mice are shown in Fig. 1C. No APJ mRNA expression was observed in $\mathrm{APJ}^{-1-}$ mice. Expression of APJ mRNA by ISHH was not detected in other peripheral $\mathrm{APJ}^{-1-}$ tissues including the lung and kidney (data not shown).

Role of APJ in fluid homeostasis in mice with free access to drinking water

Under normal conditions (WR) drinking behaviour, measured as intake in $24 \mathrm{~h}$, was significantly less in $\mathrm{APJ}^{-/-}$ mice compared with wild-type (wild-type $5 \cdot 3 \pm 0.5 \mathrm{ml} / 24 \mathrm{~h}$ per $20 \mathrm{~g}$; $\mathrm{APJ}^{-/-} 3.9 \pm 0.4 \mathrm{ml} / 24 \mathrm{~h}$ per $\left.20 \mathrm{~g} ; P<0 \cdot 05\right)$. Spontaneously voided urine volume (wild-type 1.00 $\pm 0.12 \mathrm{ml} / 24 \mathrm{~h}$ per $20 \mathrm{~g} ; \mathrm{APJ}^{-/-} 1 \cdot 02 \pm 0.14 \mathrm{ml} / 24 \mathrm{~h}$ per $20 \mathrm{~g}$ ) and urine osmolality (wild-type 3008 $\pm 165 \mathrm{mOsmol} / \mathrm{kgH}_{2} \mathrm{O} ; \mathrm{APJ}^{-/-} 3169 \pm 252 \mathrm{mOsmol} /$ $\mathrm{kgH}_{2} \mathrm{O}$ ) were comparable between genotypes (Fig. 2).

Effect of water deprivation on fluid homeostasis in wild-type and $A P J^{-1-}$ mice

Water deprivation for $24 \mathrm{~h}$ significantly decreased urine volume in wild-type mice $(0.954 \pm 0.20$ vs 0.375 $\pm 0.09 \mathrm{ml} / 24 \mathrm{~h}$ per $20 \mathrm{~g} ; P<0.01)$ but not in $\mathrm{APJ}^{-/-}$ mice $(0.891 \pm 0.18$ vs $0.668 \pm 0.15 \mathrm{ml} / 24 \mathrm{~h}$ per $20 \mathrm{~g}$; $P>0 \cdot 05$; Fig. 3). Similarly, urine osmolality was significantly increased in wild-type (3284 \pm 246 vs $5229 \pm 389 \mathrm{mOsmol} /$ $\left.\mathrm{kgH}_{2} \mathrm{O} ; P<0 \cdot 05\right)$ but not in $\mathrm{APJ}^{-1-}$ mice $(3649 \pm 351$ vs $\left.4610 \pm 674 \mathrm{mOsmol} / \mathrm{kgH}_{2} \mathrm{O} ; P>0 \cdot 05\right)$.

\section{Plasma AVP}

In WR mice, plasma AVP levels tended to be lower in APJ $^{-/-}$mice $(23 \cdot 3 \pm 6 \cdot 3 \mathrm{pg} / \mathrm{ml})$ than in wild-type $(39 \cdot 5 \pm 7 \cdot 8 \mathrm{pg} / \mathrm{ml})$, although this did not achieve statistical significance $(P=0 \cdot 138)$. Following $24 \mathrm{~h} \mathrm{WD}$, there were comparable increases in AVP concentration in both genotypes (wild-type $57 \cdot 7 \pm 3 \cdot 5 \mathrm{pg} / \mathrm{ml}$ versus $\mathrm{APJ}^{-/-}$ $52 \cdot 9 \pm 2 \cdot 9$ pg/ml; Fig. 4).

\section{Effect of $d D A V P$ on urine osmolality}

Urine osmolalities prior to dDAVP administration were comparable between wild-type and $\mathrm{APJ}^{-/-}$mice. Administration of dDAVP significantly increased urine osmolality both in wild-type (3278 $\pm 258-4635 \pm 244 \mathrm{mOsmol} /$ $\left.\mathrm{kgH}_{2} \mathrm{O} ; \quad P<0 \cdot 01\right)$ and $\mathrm{APJ}^{-/-}$mice $(2575 \pm 322-3590$ $\left.\pm 151 \mathrm{mOsmol} / \mathrm{kgH}_{2} \mathrm{O} ; P<0 \cdot 05\right)$, however the dDAVPinduced increase in $\mathrm{APJ}^{-1-}$ mice was significantly attenuated compared with wild-type $\left(\mathrm{APJ}^{-/-} 3590 \pm 151\right.$ versus wildtype $\left.4635 \pm 244 \mathrm{mOsmol} / \mathrm{kgH}_{2} \mathrm{O} ; P<0 \cdot 05\right)$. 
A

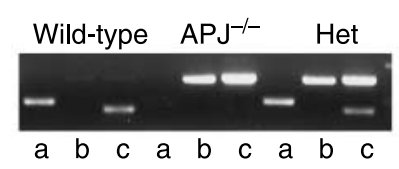

B

Pituitary

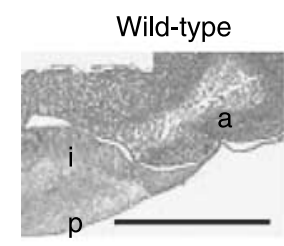

Adrenal
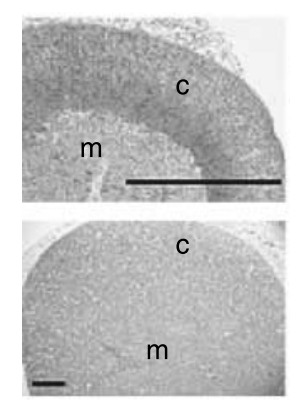

Kidney

Lung
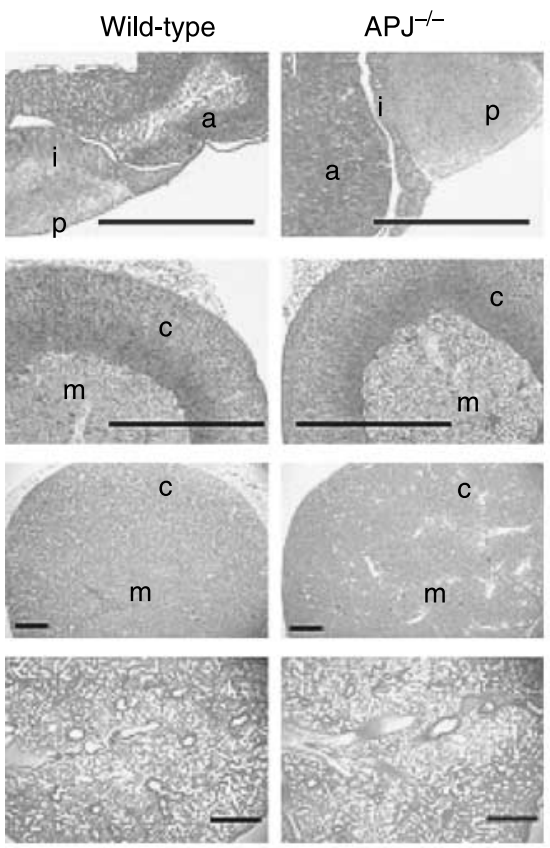

C (i)

(i) Wild-type heart (antisense)

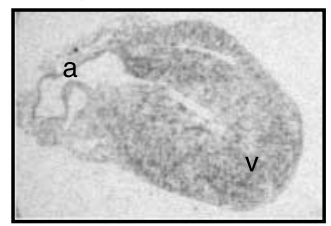

(ii) $\mathrm{APJ}^{-/-}$heart (antisense)

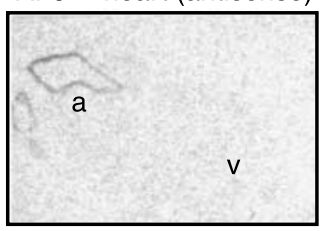

(iii) Wild-type heart (sense)

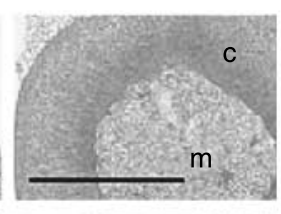

a

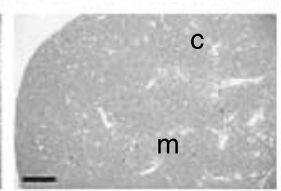

(iv) Wild-type PVN (antisense)

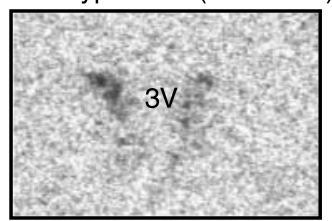

(v) $\mathrm{APJ}^{-1-} \mathrm{PVN}$ (antisense)

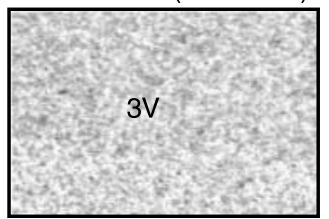

Figure 1 (A) Representative PCR of DNA extracted from tail clips from weaned pups. Image shows wild-type, heterozygous (het), and APJ knockout $\left(^{-\prime}\right)$ genotypes. DNA was isolated from tail tips and three reactions carried out for each sample: a, primers 1 and 2 to detect endogenous APJ; b, primers 3 and 4 to detect recombinant allele; and c, primers 5, 6, and 7 a multiplex reaction to detect both endogenous and targeted genes. (B) Comparable histology (H\&E) in sections of pituitary gland, adrenal gland, kidney, and lung of wild-type and $\mathrm{APJ}^{-1-}$ mice. Scale bars $=500 \mu \mathrm{m}$; a, anterior pituitary; c, cortex; i, intermediate lobe of pituitary; m, medulla; p, posterior pituitary. (C) Representative ISHH autoradiographic images showing APJ mRNA expression in sections of heart and PVN from wild-type ((i) and (iv)) and APJ ${ }^{-1-}($ (ii) and (v)) mice. No APJ mRNA expression was observed in the APJ ${ }^{-1-}$ mice. No specific labeling was seen in the wild-type control heart section using ${ }^{35}$ S-labeled sense-strand RNA control probe (iii). a, atria; $\mathrm{v}$, ventricle; $3 \mathrm{~V}$, third ventricle.

Effect of water deprivation on gene expression within the HNS of wild-type and $A P J^{-1-}$ mice

To determine the effect of WD on the regulation of HNS gene expression, ISHH was performed with specific riboprobes to detect changes in c-fos and AVP gene expression within the MnPO, SFO, SON, and PVN, all major components of the HNS. In WR mice, low levels of c-fos mRNA expression were found in all regions studied that were statistically comparable between genotypes.
WD significantly increased c-fos mRNA expression in all regions, and to a similar extent in the MnPO (wildtype $528 \cdot 9 \pm 73 \cdot 1 \% ; \mathrm{APJ}^{-1-} 395 \cdot 2 \pm 43 \cdot 7 \%$ ) and $\mathrm{SON}$ (wild-type $270 \cdot 8 \pm 32 \cdot 2 \%$ APJ $^{-1-} 349 \cdot 7 \pm 24 \cdot 4 \%$ ) of both genotypes. However, c-fos mRNA expression was significantly attenuated in the SFO and accentuated in the PVN of $\mathrm{APJ}^{-1-}$ mice versus wild-type (SFO, $\mathrm{APJ}^{-1-} 377 \cdot 8$ $\pm 61 \cdot 1 \%$ versus wild-type $981 \cdot 3 \pm 193 \cdot 7 \% P<0 \cdot 001$; PVN, $\mathrm{APJ}^{-\prime-} 254 \cdot 6 \pm 14 \cdot 2 \%$ versus wild-type $186 \cdot 5 \pm 18 \cdot 0 \%$ $P<0 \cdot 05$; Fig. 5). 

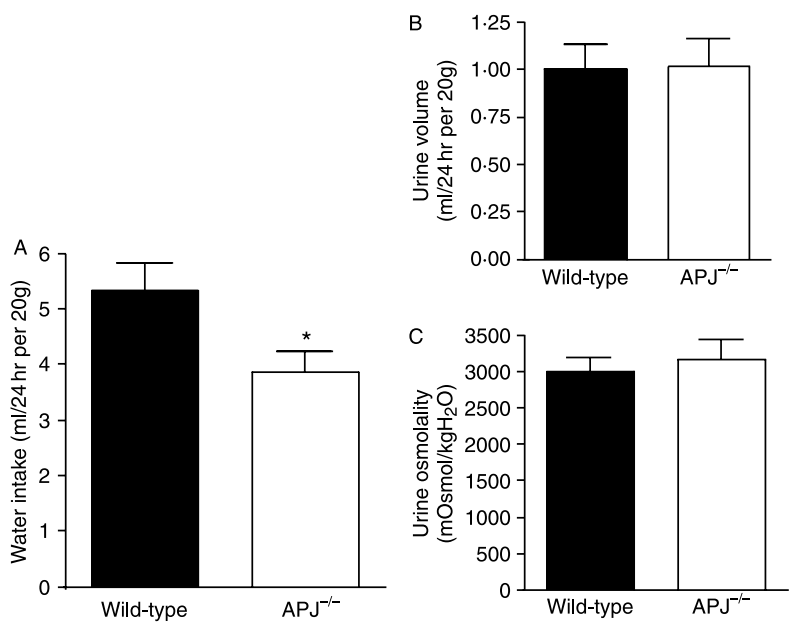

Figure 2 Fluid homeostasis in water replete wild-type (filled bars) and $\mathrm{APJ}^{-1-}$ (open bars) mice. Drinking behaviour (A) was significantly attenuated in $\mathrm{APJ}^{-1-}$ mice compared with wildtype when measured over $24 \mathrm{~h}$, however, neither urine volume (B) nor urine osmolality (C) differed between the genotypes. Data are mean \pm S.E.M., $n=16$, results of $t$-test $* P<0 \cdot 5$.

AVP mRNA levels in the SON of wild-type and $\mathrm{APJ}^{-/-}$ WR mice did not differ, but significantly higher levels were found in the $\mathrm{PVN}$ of $\mathrm{APJ}^{-/-}$mice $\left(\mathrm{APJ}^{-/-} 127 \cdot 3\right.$ $\pm 7 \cdot 4 \%$ versus wild-type $100 \cdot 0 \pm 10 \cdot 3 \%$; $t$-test $P<0 \cdot 05$, Fig. 6). WD for $24 \mathrm{~h}$ increased levels comparably in both groups in the SON, but only in the wild-type PVN. The already elevated AVP mRNA levels in the PVN of $\mathrm{APJ}^{-/-}$ mice did not respond further to the dehydration stimulus.

\section{Discussion}

This is the first study to use APJ-deficient mice to determine the role of the apelinergic system in fluid homeostasis. We have shown abnormal water metabolism in $\mathrm{APJ}^{-/-}$mice, manifested by a change in drinking behaviour and in the ability to concentrate urine. Under normal conditions, drinking behaviour was significantly reduced in mice lacking APJ, while other indices of fluid homeostasis, i.e. voided urine volume and urine osmolality remained unaltered. In addition, our results demonstrate that during periods of osmotic stress induced by dehydration the expected water deprivationassociated decrease in spontaneously voided urine volume and increase in urine osmolality did not occur in $\mathrm{APJ}^{-/-}$mice. This defect did not appear to be due to altered regulation of AVP secretion into the circulation but may involve disrupted CVO and/or hypothalamic neuroendocrine expression as well as impaired AVP receptor-activated processes in the kidney in $\mathrm{APJ}^{-/-}$mice. This study demonstrates a major physiological role for APJ in the regulation of water intake and fluid retention.

$\mathrm{APJ}^{-1-}$ mice were bred from heterozygous crosses and there were no apparent morphological differences in major organs of the $\mathrm{KO}$ mouse compared with wild-type littermates.
These findings are in accordance with other reports of comparable histology between wild-type and $\mathrm{APJ}^{-/-}$mice and are consistent with reports of comparable systolic blood pressure and heart rate in $\mathrm{APJ}^{-/-}$and wild-type mice (Ishida et al. 2004). $\mathrm{APJ}^{-/-}$mice, however, showed a variable phenotype with a loss of homozygous mutants. Surviving $\mathrm{APJ}^{-/-}$mice had a significantly lower body weight than wild-type littermates that may reflect the diuretic phenotype of these mutant mice, but showed no other obviously visible phenotype. Reduced body weight in $\mathrm{APJ}^{-/-}$mice is also consistent with a report of chronic i.c.v. apelin administration stimulating weight gain (Valle et al. 2008), but apelin's precise role in feeding behaviour remains to be resolved. Partial lethality has been previously observed in $\mathrm{KO}$ mouse models of other GPCRs expressed in the hypothalamus and/or pituitary, such as the corticosterone releasing hormone receptor 1 (Smith et al. 1998, Timpl et al. 1998). The cause of this lethality is as yet unknown and work is ongoing within our group to explain the variable phenotype.
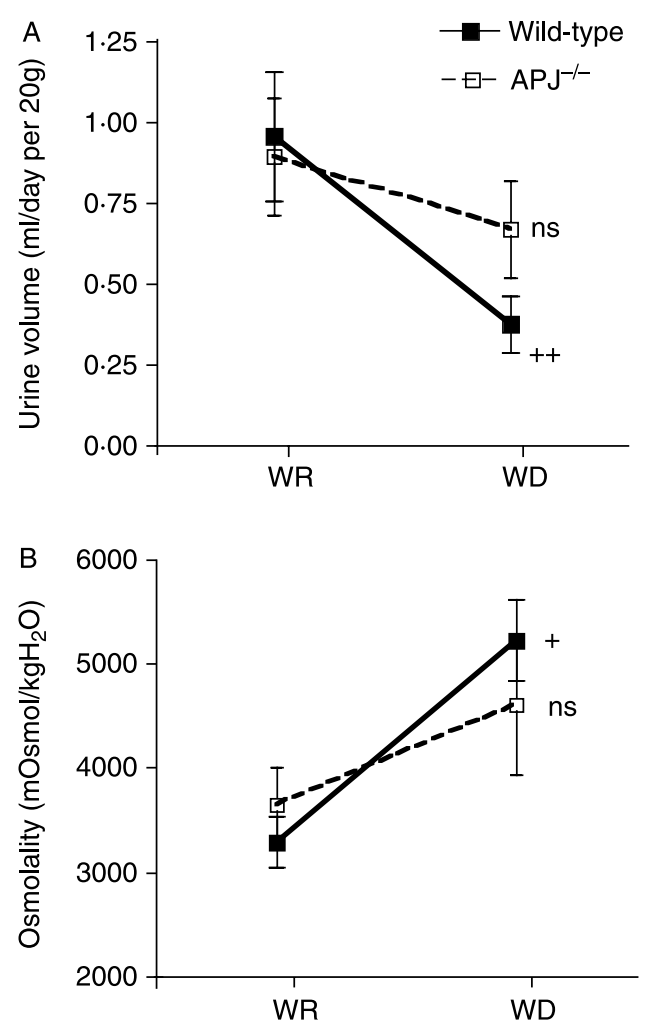

Figure 3 Effects of water deprivation on urine volume and urine osmolality. Mice were housed in metabolic cages and urine volume collected after $24 \mathrm{~h}$ with water (WR) followed by $24 \mathrm{~h}$ without water (WD). (A) WD significantly decreased spontaneously voided urine volume in wild-type (solid line) but not $\mathrm{APJ}^{-1-}$ (dotted line) mice compared with WR. (B) WD significantly increased urine osmolality in wild-type (solid line) but not $\mathrm{APJ}^{-1-}$ (dotted line) mice. Data are mean \pm S.E.M., $n=8$, results of two-way repeated measures ANOVA with Bonferroni post hoc test, ns, not significant; ${ }^{+} P<0 \cdot 05,{ }^{+}+P<0 \cdot 01 \mathrm{WD}$ versus WR. 


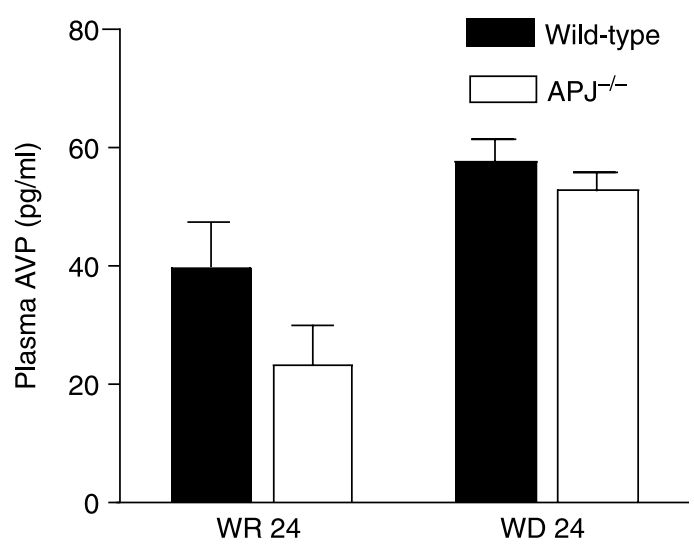

Figure 4 Plasma arginine vasopressin (AVP) concentration in wildtype (filled bars) and $\mathrm{APJ}^{-1-}$ (open bars) water replete (WR 24) mice and water deprived (WD 24) for 24 h. Data are mean \pm S.E.M., $n=6-8$, results of two-way ANOVA show significant comparable increases in both genotypes following water deprivation $(P<0 \cdot 001)$.

Our previous work suggested that aspects of the apelinergic system present in the hypothalamus where the apelinergic system is involved in fluid metabolism as dehydration was shown to be associated with a significant increase in $A P J$ mRNA expression in the SON and PVN (O'Carroll \& Lolait 2003). Specifically, involvement with the vasopressinergic system has been proposed (De Mota et al. 2004, Reaux-Le Goazigo et al. 2004, Azizi et al. 2008). The first apelin/APJ localisation studies provided clues that apelin may regulate vasopressinergic neurones activity. Apelin and APJ mRNA and protein are all highly expressed in the PVN and SON (Lee et al. 2000, O'Carroll et al. 2000, Reaux et al. 2002), and APJ mRNA and apelin protein are co-localised with AVP in both these nuclei (Reaux et al. 2001, O'Carroll \& Lolait 2003, Reaux-Le Goazigo et al. 2004). In addition, apelin immunoreactivity is found along the hypothalamo-neurohypophysial tract, in the internal zone of the median eminence and in the posterior pituitary (Reaux et al. 2001, Brailoiu et al. 2002) suggesting an involvement in the control of water balance. Effective fluid homeostasis requires the rapid secretion of AVP from the posterior pituitary into the general circulation in response to various signals, including elevated plasma osmolality, decreased extracellular fluid volume and increased AngII concentration (Antunes-Rodrigues et al. 2004). In this study, we have shown plasma AVP levels tended to be lower in $\mathrm{APJ}^{-/-}$mice than in wild-type controls under normal conditions, consistent with a recent study showing activation of AVP-neurones in the SON following administration of apelin directly onto the exposed ventral glial lamina of virgin female rats (Tobin et al. 2008). A dissociation between the excitatory effect of apelin on AVP cell body activity in vivo (implying increased AVP secretion from the pituitary) and its inhibitory effect on somatodendritic AVP release from isolated rat SON in vitro was shown, indicating differential regulation of AVP release by apelin (Tobin et al. 2008). However, conflicting results have been shown in lactating rats (De Mota et al. 2004) where an inverse relationship between plasma apelin and AVP concentrations was also reported. These effects may be dependent on the physiological conditions of the animals, as AVP levels are known to be elevated in lactating animals (Poulain et al. 1977), or on the ongoing electrical activity of vasopressinergic cells (Tobin et al. 2008).

We also observed a decrease in water intake by $\mathrm{APJ}^{-1-}$ mice in this study, consistent with the lower plasma AVP levels found in these mice and compatible with findings from other groups of increased drinking behaviour following apelin administration in the rat (Lee et al. 2000, Taheri et al. 2002), but contrary to reports of apelin-13 inhibition of dehydration-induced water intake (Reaux et al. 2001) and of unaltered drinking behaviour in another $\mathrm{APJ}^{-/-}$mouse line (Ishida et al. 2004). Inconsistent findings with regard to drinking behaviour may be due to differences in models used, species or strain of rat (Lee et al. 2000, Reaux et al. 2001, Taheri et al. 2002, Ishida et al. 2004, Mitra et al. 2006, Clarke et al. 2009). The contrasting findings on the role of the apelinergic system in drinking behaviour may also reflect the activity at distinct populations of APJ, for example i.c.v. apelin may manifest a direct effect at central APJ populations whereas peripheral administration may modulate different functions that are dependent on regional tissue site expression.

We then investigated the role of APJ in the regulation of water balance during water deprivation when endogenous levels of AVP are increased. Neurones in the SON respond electrophysiologically, functionally, and morphologically to osmotic perturbations (Dyball \& Pountney 1973, Hatton et al. 1978, Bourque \& Renaud 1984), and magnocellular neuroendocrine cells in this region produce the majority

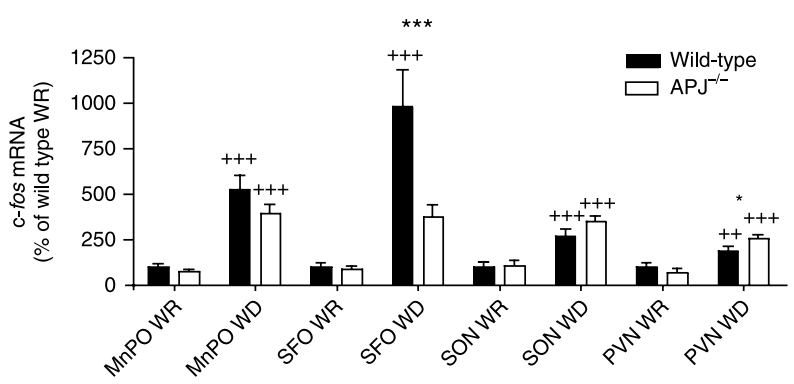

Figure 5 Effect of water deprivation (WD) on expression of c-fos mRNA in the MnPO, SFO, SON, and PVN. Expression of c-fos mRNA was negligible in water replete (WR) wild-type (filled bars) and $\mathrm{APJ}^{-1-}$ (open bars) mice. WD caused comparable increases in c-fos mRNA in the MnPO and SON of wild-type and APJ ${ }^{-/-}$mice, however, the WD-induced significant increase in c-fos mRNA expression was significantly reduced in the SFO of $\mathrm{APJ}^{-1-}$ mice compared with wild-type, while in the PVN c-fos expression was accentuated in $\mathrm{APJ}^{-/}$mice. The graph shows expression of c-fos mRNA calculated as a percentage of wild-type/WR in the MnPO $(n=3)$, SFO $(n=3)$, SON $(n=4-5)$, and PVN $(n=4-6)$. Data are mean \pm S.E.M. of 2-4 images per animal and were analyzed using two-way ANOVA and Bonferroni post hoc tests: $* P<0 \cdot 05$,

${ }^{* * *} P<0 \cdot 001$ wild-type versus APJ ${ }^{-1-} ;{ }^{++} P<0 \cdot 01,{ }^{++}+P<0 \cdot 001$ WR versus WD. 
Wild-type $\mathrm{APJ}^{-1-}$

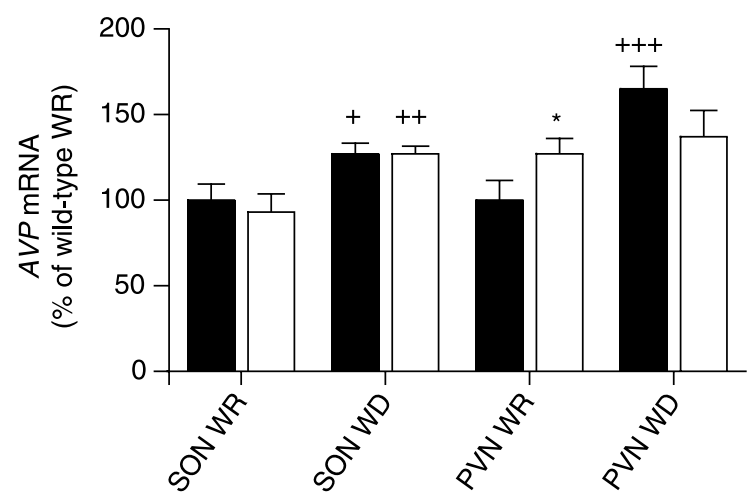

Figure 6 Expression of arginine vasopressin (AVP) mRNA in the PVN and SON of wild-type (filled bars) and $\mathrm{APJ}^{-1-}$ (open bars) mice housed in metabolic cages with (WR) or without (WD) free access to drinking water for $24 \mathrm{~h}$. The graph shows expression of AVP mRNA calculated as a percentage of wild-type/WR in the SON $(n=4-5)$ and PVN $(n=4)$. Data are mean \pm S.E.M. of 2-4 images per animal, result of $t$-test to compare basal AVP mRNA expression ${ }^{*} P<0 \cdot 05$; comparisons between genotypes and treatment groups were made using two-way ANOVA and Bonferroni post hoc test, ${ }^{+} P<0 \cdot 05,{ }^{+}+P<0 \cdot 01,{ }^{+}+{ }^{+} P<0 \cdot 001 \mathrm{WR}$ versus WD.

of AVP secreted into the systemic circulation (AntunesRodrigues et al. 2004). Hyperosmotic and hypovolemic stimulation increase the secretion of AVP and decrease peptide content and immunoreactivity in the SON and PVN (De Mota et al. 2004, Reaux-Le Goazigo et al. 2004). We show that while water deprivation significantly decreased urine volume and increased urine osmolality in wild-type controls, $\mathrm{APJ}^{-1-}$ mice were unable to concentrate their urine to the same extent. This defect in water homeostasis did not appear to be due to an inability of these animals to increase plasma AVP levels as comparable increases were seen in both genotypes following water deprivation, suggesting the presence of an intact central AVP system in $\mathrm{APJ}^{-/}$mice. Thus, factors other than central interactions between the apelinergic and vasopressinergic systems may contribute to apelinergic regulation of fluid homeostasis. However, our data contrast with other studies in which an increase in diuresis is seen after apelin administration to lactating female rats (De Mota et al. 2004, Hus-Citharel et al. 2008). As with drinking behaviour, these differences may be due to the physiological conditions of the animals.

As the defect in water metabolism seen in $\mathrm{APJ}^{-/-}$mice did not appear to be due to altered AVP neurosecretory function, we investigated the possibility of a defect in renal mechanisms in the mutant mice. Pronounced APJ and apelin gene expression occur within peripheral tissues as well as within the CNS. Both apelin and APJ mRNA have previously been detected in the rat kidney associated with glomeruli in the cortex, in cells of the vasa recta in the inner stripe of the outer medulla, along the nephron including the collecting ducts and in glomerular arterioles (Hosoya et al. 2000, Lee et al. 2000, O'Carroll et al. 2000, Kawamata et al. 2001, Medhurst et al. 2003, Hus-Citharel et al. 2008). Using RT-PCR, apelin and APJ mRNA have also been identified in mouse kidney (Medhurst et al. 2003). The strong expression of $A P J \mathrm{mRNA}$ in the kidney suggests an involvement of peripheral aspects of the apelinergic system in the regulation of fluid homeostasis. To determine whether the defect observed in $\mathrm{APJ}^{-/-}$mice may be due to a role of $\mathrm{APJ}$ in regulating renal $\mathrm{V} 2$ receptors, the renal responses of $\mathrm{APJ}^{-/-}$mice to the AVP V2 receptor agonist dDAVP were examined. Peripheral administration of dDAVP induced an increase in urine osmolality indicative of increased fluid retention in $\mathrm{APJ}^{-/-}$mice; however, this increase was not as great as that seen in wild-type mice indicating an attenuation of $\mathrm{V} 2$ receptor-associated pathways in $\mathrm{APJ}^{-1-}$ mice.

In the HNS, the physiological effects of apelin appear to be mediated via AVP, perhaps by a direct action on APJcontaining vasopressinergic PVN neurones (O'Carroll \& Lolait 2003). To determine whether central APJ receptors are essential for AVP neuronal function, we investigated the neurosecretory system under basal and osmotically stimulated conditions. Increased expression of the immediate early gene c-fos can be used as a marker of neuronal activation to identify central nuclei involved in mediating stress responses (Wilson et al. 2002) and was used in this study, alongside AVP mRNA levels, as an index of activity in regions involved in the central regulation of water homeostasis including the PVN, SON, $\mathrm{MnPO}$, and SFO. AVP release from the magnocellular neurones during periods of osmotic stress is under the control of various aspects of the lamina terminals (McKinley et al. 2004). Neurones originating in the SFO, MnPO, and OVLT have direct efferent connections to the magnocellular SON and PVN, in addition there is a high degree of interconnectivity between these regions forming a complex osmoregulatory unit (Bourque et al. 1994). As expected, low levels of c-fos mRNA expression were seen in the SON, PVN, MnPO, and SFO of both wild-type and $\mathrm{APJ}^{-/-} \mathrm{WR}$ mice. Neuronal activation, using dehydration as a stimulus, was seen as an increase in c-fos mRNA levels in all regions. However, this response was attenuated in the $\mathrm{SFO}$ of $\mathrm{APJ}^{-/-}$ mice, suggesting that APJ is required for dehydration-induced signaling in this key structure involved in the regulation of body fluid balance. An accentuated c-fos response was seen in the $\mathrm{PVN}$ of $\mathrm{APJ}^{-1-}$ mice, indicative of increased activity compared with wild-type. However, in this instance it was not possible to distinguish whether this specific increase originated from magnocellular or parvocellular neurones so it remains unclear as to the extent that this change might be connected to fluid metabolism. Interestingly, vasopressinergic activity within the PVN was affected in $\mathrm{APJ}^{-/-}$mice as $A V P$ mRNA levels in the PVN of these mice were elevated under basal conditions but failed to respond to the dehydration stimulus implying disruption of vasopressinergic systems in the absence of APJ. APJ activity in the SFO, PVN, and other brain regions may also be influenced either directly or 
indirectly by afferent inputs - which may include the effects of apelin/APJ acting in an autocrine, paracrine, or neuromodulatory manner.

We observed that under normal conditions with free access to drinking water, $\mathrm{APJ}^{-/-}$mice drank less than, but excreted comparable amounts of urine as, wild-type controls. As plasma AVP levels tended to be lower in WR $\mathrm{APJ}^{-/-}$mice than in controls, it is tempting to speculate that removal of APJ has created a modified adipsic diabetes insipidus-like phenotype, a condition characterised clinically by the failure to generate the sensation of thirst in conjunction with hypotonic polyuria due to AVP deficiency (Crowley et al. 2007). Loss of thirst leads to failure to respond to diuresis with appropriate fluid intake and to the development of hypernatremia (Crowley et al. 2007). Although not possible to measure in this study due to small plasma volumes, it would be interesting to determine plasma osmolality and sodium concentrations in the $\mathrm{APJ}^{-1-}$ mice. Recently, apelin has been identified in adipocytes and pancreatic islets and implicated in insulin-sensitive pathophysiologies, while plasma apelin concentrations have been found to be reduced in newly diagnosed type 2 diabetes mellitus (Boucher et al. 2005, Erdem et al. 2008).

In addition to involvement with vasopressinergic systems, apelin and APJ have also been linked to the renin-angiotensin system. In another APJ-deficient model, $\mathrm{APJ}^{-1-}$ mice displayed an enhanced vasopressor response to systemic AngII, suggesting a counter-regulatory action of apelin on AngII (Ishida et al. 2004). Additionally, apelin has been reported to regulate glomerular hemodynamic function in the rat kidney (Hus-Citharel et al. 2008). Circulating AngII activates the HNS and stimulates thirst and fluid retention via receptors located in the CVOs and subsequent release of AVP (Antunes-Rodrigues et al. 2004, McKinley et al. 2004). Mice lacking the AngII AT1 $\mathrm{a}^{-/-}$receptor have increased water intake, increased urine output, and decreased urine osmolality compared with controls under WR conditions and exhibit a deficit in their ability to concentrate urine in response to water deprivation (Oliverio et al. 2000). Increased activity within the PVN, measured by both c-fos-immunoreactivity and $A V P$ mRNA expression, in AT1 $\mathrm{a}^{-1-}$ mice following water deprivation further highlights the complexity of fluid metabolism (Morris et al. 2001). Despite the SFO and MnPO being key sites of AngII activity during fluid metabolism and AVP secretion there was no significant effect on cellular activity within these regions in AT1 $\mathrm{a}^{-1-}$ mice (Morris et al. 2001). Emerging data thus indicate opposing roles for the apelinergic and renin-angiotensin systems (Hus-Citharel et al. 2008).

In conclusion, our study is an important step towards defining the physiological role of APJ in neurophyophysial function using APJ deficient mice. We have shown abnormal water metabolism in $\mathrm{APJ}^{-1-}$ mice, possibly as a result of altered central neuroendocrine expression and disruption of the central AVP response to osmotic stimulus, as well as impaired AVP receptor-activated processes in the kidney.
Our data demonstrate a physiological role for APJ in central and peripheral mechanisms of water intake and fluid retention and suggest a novel anti-diuretic effect of apelin in vivo. While a targeted approach for gene knockdown would possibly circumvent the confounding effects found in global KO models, suitable tissue- or brain-region-specific Cre lines that would enable construction of relevant conditional APJ-KOs are not available and there is a paucity of APJ-selective ligands with which to explore the physiological role of APJ. The APJ ${ }^{-/-}$mice should provide a useful model to investigate the role of apelin in other aspects of hypothalamic function.

\section{Declaration of interest}

There is no conflict of interest that could be perceived as prejudicing the impartiality of the research reported.

\section{Funding}

This work was supported by The Wellcome Trust (grant numbers 076321 and 074690) and the Biotechnology and Biological Sciences Research Council (grant number BB/D00196X/1).

\section{References}

Antunes-Rodrigues J, De Castro M, Elias LK, Valença MM \& McCann SM 2004 Neuroendocrine control of body fluid metabolism. Physiological Reviews 84 169-208.

Azizi M, Iturrioz X, Blanchard A, Peyrard S, De Mota N, Chartel N, Vaudry H, Corvol P \& Llorens-Cortes C 2008 Reciprocal regulation of plasma apelin and vasopressin by osmotic stimuli. Journal of the American Society of Nephrology 19 1015-1024.

Boucher J, Masri B, Daviaud D, Gesta S, Guigné C, Mazzucotelli A, Castan-Laurell I, Tack I, Knibiehler B, Carpéné C et al. 2005 Apelin, a newly identified adipokine up-regulated by insulin and obesity. Endocrinology 146 1764-1771.

Bourque CW \& Renaud LP 1984 Activity patterns and osmosensitivity of rat supraoptic neurones in perfused hypothalamic explants. Journal of Physiology 349 631-642.

Bourque CW, Oliet SHR \& Richard D 1994 Osmoreceptors, osmoreception and osmoregulation. Frontiers in Neuroendocrinology 15 231-274.

Brailoiu GC, Dun S, Yang J, Ohsawa M, Chang JK \& Dun NJ 2002 Apelin-immunoreactivity in the rat hypothalamus and pituitary. Neuroscience Letters 327 193-197.

Burbach JPH, Luckman SM, Murphy D \& Gainer H 2001 Gene-regulation in the magnocellular hypothalamo-neurohypophsial system. Physiological Reviews 81 1197-1267.

Clarke KJ, Whitaker KW \& Reyes TM 2009 Diminished metabolic responses to centrally-administered apelin-13 in diet-induced obese rats fed a high fat diet. Journal of Neuroendocrinology 21 83-89.

Crowley RK, Sherlock M, Agha A, Smith D \& Thompson CJ 2007 Clinical insights into adipsic diabetes insipidus: a large case series. Clinical Endocrinology 66 475-482.

Devic E, Rizzoti K, Bodin S, Knibehler B \& Audigier Y 1999 Amino acid sequence and embryonic expression of msr/apj, the mouse homolog of Xenopus X-msr and human APJ. Mechanisms of Development 84 199-203.

Dyball RE \& Pountney PS 1973 Discharge patterns of supraoptic and paraventricular neurones in rats given a 2 per cent $\mathrm{NaCl}$ solution instead of drinking water. Journal of Endocrinology 56 91-98. 
Erdem G, Dogru T, Tasci I, Sonmez A \& Tapan S 2008 Low plasma apelin levels in newly diagnosed type 2 diabetes mellitus. Experimental and Clinical Endocrinology and Diabetes 116 289-292.

Habata YH, Fujii R, Hosoya M, Fukusumi S, Kawamata Y, Hinuma S, Kitada C, Nishizawa N, Murosaki S, Kurokawa T et al. 1999 Apelin, the natural ligand of the orphan receptor APJ, is abundantly secreted in the colostrum. Biochimica et Biophysica Acta 1452 25-35.

Hatton GI, Armstrong WE \& Gregory WA 1978 Spontaneous and osmotically-stimulated activity in slices of rat hypothalamus. Brain Research Bulletin 3 497-508.

Hosoya M, Kawamata Y, Fukusumi S, Fujii R, Habata Y, Hinuma S, Kitada C, Honda S, Kurokawa T, Onda H et al. 2000 Molecular and functional characteristics of APJ. Tissue distribution of mRNA and interaction with the endogenous ligand apelin. Journal of Biological Chemistry 275 21061-21067.

Hus-Citharel A, Bouby N, Frugière A, Bodineau L, Gasc J-M \& Llorens Cortes C 2008 Effect of apelin on glomerular hameodynamic function in the rat kidney. Kidney International 74 486-494.

Ishida J, Hashimoto T, Hashimoto Y, Nishiwaki S, Iguchi T, Harada S, Sugaya T, Matsuzaki H, Yamamoto R, Shiota N et al. 2004 Regulatory roles for APJ, a seven-transmembrane receptor related to angiotensintype 1 receptor in blood pressure in vivo. Journal of Biological Chemistry 279 26274-26279.

Kawamata Y, Habata Y, Fukusumi S, Hosoya M, Fujuu R, Hinuma S, Nishizawa N, Kitada C, Onda H, Nishimura O et al. 2001 Molecular properties of apelin: distribution and receptor binding. Biochimica et Biophysica Acta 1538 162-171.

Knepper MA \& Inoue T 1997 Regulation of aquaporin-2 water channel trafficking by vasopressin. Current Opinion in Cell Biology 9 560-564.

Kuba K, Zhang L, Imai Y, Arab S, Chen M, Maekawa Y, Leschnik M, Leibbrandt A, Markovic M, Schwaighofer J et al. 2007 Impaired heart contractility in apelin gene-deficient mice associated with aging and pressure overload. Circulation Research 101 e32-e42.

Landgraf R, Kubota M, Holsboer F \& Wotjak CT 1995 Release of vasopressin and oxytocin within the brain and into blood: microdialysis and antisense targeting. In Neurohypophysis: Recent Progress of Vasopressin and Oxytocin Research, pp 243-256. Eds T Saito, K Kurokawa \& $S$ Yoshida. Amsterdam: Elsevier.

Lee DK, Cheng R, Nguyen T, Fan T, Kariyawasam AP, Liu Y, Osmond DH, George SR \& O'Dowd BF 2000 Characterisation of apelin, the ligand for the APJ receptor. Journal of Neurochemistry 74 34-41.

McKinley MJ, Mathai ML, McAllen RM, McClear RC, Miselis RR, Penninton GL, Vivas L, Wade LD \& Oldfield BJ 2004 Vasopressin secretion: osmotic and hormonal regulation by the lamina terminalis. Journal of Neuroendocrinology 16 340-347.

Medhurst AD, Jennings CA, Robbins MJ, Davis RP, Ellis C, Winborn KY, Lawrie KW, Hervieu G, Riley G, Bolaky JE et al. 2003 Pharmacological and immunohistochemical characterisation of the APJ receptor and its endogenous ligand apelin. Journal of Neurochemistry 84 1162-1172.

Mitra A, Katovich MJ, Mecca A \& Rowland NE 2006 Effects of central and peripheral injections of apelin on fluid intake and cardiovascular parameters in rats. Physiology and Behavior 89 221-225.

Morris M, Means S, Oliverio MI \& Coffman TM 2001 Enhanced central response to dehydration in mice lacking angiotensin AT1a receptors. American Journal of Physiology. Regulatory, Integrative and Comparative Physiology 280 R1177-R1184.

De Mota N, Lenkei Z \& Llorens-Cortes C 2000 Cloning, pharmacological characterisation and brain distribution of the rat apelin receptor. Neuroendocrinology 72 400-407.

De Mota N, Reaux-Le Goazigo A, El Messari S, Chartrel N, Roesch D, Dujardin C, Kordon C, Vaudry H, Moos F \& Llorens-Cortes C 2004 Apelin, a potent diuretic neuropeptide counteracting vasopressin actions through inhibition of vasopressin neurones activity and vasopressin release. PNAS 101 10464-10469.

O'Carroll A-M \& Lolait SJ 2003 Regulation of rat APJ receptor messenger ribonucleic acid expression in magnocellular neurones of the paraventricular and supraoptic nuclei by osmotic stimuli. Journal of Neuroendocrinology 15 661-666.
O'Carroll A-M, Selby TL, Palkovits M \& Lolait SJ 2000 Distribution of mRNA encoding B78/apj, the rat homologue of the human APJ receptor, and its endogenous ligand apelin in brain and peripheral tissues. Biochimica et Biophysica Acta 1492 72-80.

O'Dowd BF, Heiber M, Chan A, Heng HHQ, Tsui L-C, Kennedy JL, Shi X, Petronis A, George SR \& Nguyen T 1993 A human gene that shows identity with the gene encoding the angiotensin receptor is located on chromosome 11. Gene 136 355-360.

Oliverio M, Delnomdedieu M, Best CF, Li P, Morris M, Callahan MF, Johnson A, Smithies O \& Coffman TM 2000 Abnormal water metabolism in mice lacking the type $1 \mathrm{~A}$ receptor for ANG II. American Journal of Physiology. Renal Physiology 278 F75-F82.

Poulain DA, Wakerley JB \& Dyball RE 1977 Electrophysiological differentiation of oxytocin- and vasopressin-secreting neurones. Proceedings of the Royal Society of London. Series B. Biological Sciences 196 367-384.

Reaux A, De Mota N, Skultetyova I, Lenkei Z, El Messari S, Gallatz K, Corvol P, Palkovits M \& Llorens-Cortes C 2001 Physiological role of a novel neuropeptide, apelin, and its receptor in the rat brain. Journal of Neurochemistry 77 1085-1096.

Reaux A, Gallatz K, Palkovits M \& Llorens-Cortes C 2002 Distribution of apelin-synthesising neurones in the adult rat brain. Neuroscience $\mathbf{1 1 3}$ 653-662.

Reaux-Le Goazigo A, Morinville A, Burlet A, Llorens-Cortes C \& Beaudet A 2004 Dehydration-induced cross-regulation of apelin and vasopressin immunoreactivity levels in magnocellular hypothalamic neurones. Endocrinology 145 4392-4400.

Smith GW, Aubry JM, Dellu F, Contarino A, Bilezikjian LM, Gold LH, Chen R, Marchuk Y, Hauser C, Bentley CA et al. 1998 Corticotropin releasing factor receptor 1-deficient mice display decreased anxiety, impaired stress response, and aberrant neuroendocrine development. Neuron 20 1093-1102.

Taheri S, Murphy K, Cohen M, Sujkovic E, Kennedy A, Dhillo W, Dakin C, Sajedi A, Ghatei M \& Bloom S 2002 The effects of centrally administered apelin-13 on food intake, water intake and pituitary hormone release in rats. Biochemical and Biophysical Research Communications 291 1208-1212.

Takayama K, Iwazaki H, Hirabayashi M, Yakabi K \& Ro S 2007 Distribution of c-Fos immunoreactive neurones in the brain after intraperitoneal injection of apelin-12 in Wistar rats. Neuroscience Letters 431 247-250.

Tatemoto K, Hosoya M, Habata Y, Fujii R, Kakegawa T, Zou MX, Kawamata Y, Fukusumi S, Hinuma S, Kitada C et al. 1998 Isolation and characterization of a novel endogenous peptide ligand for the human APJ receptor. Biochemical and Biophysical Research Communications 251 471-476.

Timpl P, Spanagel R, Sillaber I, Kresse A, Reul JM, Stalla GK, Blanquet V, Steckler T, Holsboer F \& Wurst W 1998 Impaired stress response and reduced anxiety in mice lacking a functional corticotropin-releasing hormone receptor 1. Nature Genetics 19 162-166.

Tobin VA, Bull PM, Arunachalam S, O'Carroll A-M, Ueta Y \& Ludwig M 2008 The effects of apelin on the electrical activity of hypothalamic magnocellular vasopressin and oxytocin neurones and somatodendritic peptide release. Endocrinology 149 6136-6145.

Valle A, Hoggard N, Adams AC, Roca P \& Speakman JR 2008 Chronic central administration of apelin-13 over 10 days increases food intake, body weight, locomotor activity and body temperature in C57BL/6 mice. Journal of Neuroendocrinology 20 79-84.

Wilson Y, Nag N, Davern P, Oldfield BJ, McKinley MJ, Greferath U \& Murphy M 2002 Visualisation of functionally activated circuitry in the brain. PNAS 99 3252-3257.

Zou MX, Liu HY, Haraguchi Y, Soda Y, Tatemoto K \& Hoshino H 2000 Apelin peptides block the entry of human immunodeficiency virus (HIV). FEBS Letters 473 15-18.

Received in final form 26 May 2009

Accepted 3 July 2009

Made available online as an Accepted Preprint 3 July 2009 